UDC 338.432:631.11(477)

LBC 65.9(4Poc)

\title{
ON THE STRATEGIC DEVELOPMENT OF FOOD INDUSTRY ENTERPRISES
}

\author{
Dmytriy V. Nekhaychuk \\ Crimean Business Institute, Sovkhoznoe Village, Simferopol Region, Republic of Crimea, Russian Federation \\ Yuliya S. Nekhaychuk \\ Crimean Federal University named after V.I. Vernadsky, Simferopol, Republic of Crimea, Russian Federation
}

\begin{abstract}
The article delas with the issues of strategic development of enterprises on the example of the food industry companies. The work suggests the classification of the factors influencing the strategy planning into internal and external ones, which, in their turn, can affect the quantitative indicators established by the enterprise as the objectives.

It is clarified that taking into account the financial capabilities of the enterprise in strategic planning will allow to evaluate strategic ones more realistically. It is shown that the ultimate tasks of strategic planning are to correspond to the real capabilities of the enterprise and they are to be aimed at maximizing the use of the existing potential of the enterprise.

When planning a corporate strategy, the main goal should be to create a different way of development, based on all resources and skills, which is the opposite of environmental constraints. The study also shows the company's strategies in conditions of uncertain external environment.

The investigation identifies some strategic goals that are the initial objectives of strategic planning, namely, it focuses on attractive markets, increasing the market segment, and retaining the existing market positions. It is proved that the preference for a specific development strategy of the industry depends on the existing positions and the positions that will be achieved as a result of the implementation of the previous strategies, the specifications of the goods circulating in the market, the market conditions and the degree of its competition, the development of state regulation, and the resource potential of the industry.

As for the food industry enterprises, when choosing a strategy, it is suggested to use the following methods: "assessing the impact of macro-environment factors", "determining the driving forces of the industry", "clarifying and evaluating the key factors of success" and "determining the influence groups".

Key words: enterprise strategy, development, industry, influence of factors, competition, external and internal environment.
\end{abstract}

УДК 338.432:631.11(477)

ББК 65.9(4Poc)

К ВОПРОСУ СТРАТЕГИЧЕСКОГО РАЗВИТИЯ ПРЕДПРИЯТИЙ ПИЩЕВОЙ ИНДУСТРИИ

\author{
Дмитрий Валериевич Нехайчук \\ Крымский институт бизнеса, с. Совхозное, Симферопольский район, Республика Крым, \\ Российская Федерация
}

Юлия Серафимовна Нехайчук

Крымский федеральный университет им. В.И. Вернадского, г. Симферополь, Республика Крым, Российская Федерация

Аннотация. В исследовании рассмотрены вопросы стратегического развития предприятий на примере компаний пищевой индустрии. Предложено классифицировать факторы влияния при планировании страте- 
гии на внутренние и внешние, которые, в свою очередь, могут повлиять на количественные показатели, установленные организацией как целевые ориентиры.

Выяснено, что учет финансовых возможностей предприятия при стратегическом планировании позволит более реалистично оценивать стратегические цели. Показано, что выходные задачи стратегического планирования должны соответствовать реальным возможностям предприятия и быть направлены на максимально возможное использование имеющегося потенциала предприятия.

Основной целью при планировании корпоративной стратегии должно быть создание отличного от других пуги развития, который основывается на всех ресурсах и навыках, что является противопоставлением ограничений окружающей среды. В исследовании также показаны стратегии предприятия в условиях неопределенности внешней среды.

Выявлены некоторые стратегические цели, выступающие исходными задачами стратегического планирования, а именно: концентрация на привлекательных рынках, увеличение рыночного сегмента, удержание существующих рыночных позиций. Доказывается, что предпочтение определенной стратегии развития отрасли зависит от существующих позиций и позиций, которые будут достигнуты в результате реализации предыдущих стратегий, специфики товаров, работающих на рынке, состояния рынка и степени конкурентной борьбы на нем, развития государственного регулирования, ресурсного потенциала отрасли.

Для предприятий пищевой промышленности предлагается при выборе стратегии использовать такие методики, как «оценка влияния факторов макросреды», «определение движущих сил отрасли», «выяснение и оценка ключевых факторов успеха» и «определение групп влияния».

Ключевые слова: стратегия предприятия, развитие, промышленность, влияние факторов, конкуренция, внешняя и внутренняя среда.

Усиление конкурентной борьбы на рынке продуктов питания ставит новые требования в части планирования деятельности предприятий пищевой промышленности и переработки сельскохозяйственной продукции. Приобретение предприятием рыночных преимуществ, которые обеспечивают его устойчивость не только в краткосрочном периоде, но и в перспективе, возможно за счет целенаправленной деятельности, которая в наибольшей степени учитывает подвижность внешней среды и возможность адаптации к изменениям, которые в ней происходят, и способствует как можно большему использованию потенциала предприятия.

Учитывая это, в последнее время все большее значение приобретает использование стратегического планирования в деятельности предприятия. Для определения достижимых стратегических целей и формулирования критериев построения стратегических планов необходимо учитывать ресурсные возможности предприятий, в том числе и финансовые. Изменение форм собственности и расширение полномочий менеджмента на предприятиях привели к возникновению более широкого круга участников стратегического процесса, стратегические цели которых часто противоречивы. Кроме того, эффективность реализации стратегических планов будет зависеть от заинтересованности участников производ- ственного процесса в достижении общеорганизационных стратегических целей.

Учет интересов всех участников стратегического процесса требует подходов к разработке и реализации стратегических планов, строящихся на целевых ориентирах, которые в равной степени удовлетворяли бы интересы каждого из них. Одной из мотивационных сил, осуществляющих целенаправленное движение предприятия, может стать установление в качестве ориентиров стратегического планирования финансовых целей. Именно финансовые цели при стратегическом планировании объединяют интересы всех участников стратегического процесса и позволяют определить место каждого из них.

Учет финансовых возможностей предприятия при стратегическом планировании позволит более реалистично оценивать стратегические возможности предприятия и формулировать реальные цели как для предприятия в целом, так и для каждого участника стратегического процесса.

Вопросы разработки и реализации стратегических планов предприятия длительное время находятся в центре внимания ученых мира. Решением этой проблемы в разное время занимались представители экономических школ различных стран. Так, этой проблематике посвящены труды экономистов-теорети- 
ков и научные разработки экономистов-практиков. Среди известных ученых, которые занимались вопросами стратегического менеджмента, следует отметить таких, как М. Альберт, Б. Альстренд, И. Ансофф, А. Бандурин, Т. Баязитов, К. Боумен, С. Валек, Л. Довгань, Г.Я. Гольдштейн, Ф. Глюк, П. Дойль, И. Игнатьева, С. Кауфман, С. Кукура, Дж. Лемпел, М. Мартыненко, А. Мартинов, Г. Минцберг, М. Мескон, В. Немцов, Г.В. Осовская, М. Портер, А. Срикленд III, А. Томпсон, М. Туленков, Р. Фатхутдинов, Ф. Хедоури, А. Чандлер, Б. Чуб, 3. Шершнева и др.

При этом отсутствие теоретических наработок и практического опыта формулирования стратегических задач и формирования стратегических планов не позволяет использовать механизмы ограничения негативных последствий при планировании и реализации стратегий.

Современный потребительский рынок характеризуется усилением конкурентного предложения, что выражается в:

- росте сложности предложения и предоставляемых услуг;

- росте требований к системе менеджмента качества;

- сокращении продолжительности этапов жизненного цикла товаров (ЖЦТ);

- росте капиталоемкости производства;

- расширении ассортимента продукции и услуг.

При этом на рынке выживают предприятия, которые имеют устойчивые конкурентные преимущества. Именно стратегическое планирование должно обеспечивать выживаемость предприятия, отслеживание намеченных ориентиров развития и достижения длительного, устойчивого конкурентного преимущества. По мнению многих ученых, качественная стратегия выступает основным конкурентным преимуществом $[1 ; 6 ; 11]$, поэтому стратегия должна быть ориентирована на создание и усиление долгосрочного конкурентного статуса на рынке.

Обеспечение такого статуса возможно в том случае, когда предприятие имеет определенный стратегический потенциал. Именно он будет определять возможности достижения определенных стратегических целей и направления стратегического развития предприятия. Поэтому при определении основных стратегических направлений развития должен учитываться потенциал предприятия.

Потенциал предприятия складывается из ресурсов и источников их пополнения, которые есть в распоряжении предприятия, их связей, положения и организационной системы в целом. Потенциал выступает источником формирования конкурентного преимущества предприятий и именно поэтому требует постоянного развития и усовершенствования [11].

По мнению В. Марковой и С. Кузнецовой, составляющими потенциала организации являются как системные элементы (структуры, функции, технологии, люди), так и ресурсы, которые она может накапливать и использовать для достижения конкурентных преимуществ (входы, выходы) [6].

А. Виханский отмечает, что конкурентные преимущества предприятия определяются стратегическим потенциалом предприятия и детерминантами внешней среды. По мнению автора, существующий потенциал является стратегическим ресурсом организации, который обеспечивает устойчивость организации при непредвиденных изменениях макросреды и позволяет нейтрализовать его негативное влияние, используя позитивные изменения для усиления конкурентных позиций [2].

Стратегическая ситуация предприятия формируется исходя из выводов относительно важности отдельных факторов и их влияния на стратегию; идентификации и оценки стратегических инициатив; определения стратегии, которая соответствует ситуации.

Обобщая взгляды на факторы, которые определяют стратегию, осуществляют комплексное взаимодействие и имеют специфические отличия для отрасли и предприятия, предлагается следующая классификация факторов влияния при планировании стратегии:

- внешние (социальные, политические, демографические, общественные условия и законодательство; состояние развития НТП; экономическое развитие страны; степень государственного регулирования; привлекательность отрасли, в которой работает предприятие; конкурентные условия; возможности и ловушки для предприятия; доступность ресурсов);

- внутренние (сильные и слабые стороны предприятия, конкурентная рыночная по- 
Д.В. Нехайчук, Ю.С. Нехайчук. К вопросу стратегического развития предприятий пищевой индустрии

зиция; персональные амбиции собственников и менеджмента; философия бизнеса; этические принципы, которые исповедуют заинтересованные лица; стоимость предприятия; культура предприятия).

Стратегическое планирование, как уже отмечалось, имеет свои цели, методы, принципы, средства и инструменты.

Различные стратегии имеют различные ключевые показатели, то есть они направляются на достижение различных целей, однако и до сих пор не существует единых критериев их определения. Наиболее исследована проблема определения стратегических целей в работе И. Ансоффа «Новая корпоративная стратегия» [1]. В ней он отмечает, что по мере осложнения ситуации на рынках происходили изменения в формулировке стратегических целей. И. Ансофф предлагает построение дерева целей при планировании организационной стратегии. Он отмечает, что «для решения стратегических проблем цели используются как критерий при принятии решений о необходимости изменений, суждений или расширение рыночной политики компании» [1].
Для правильного выбора целей организационной стратегии необходимо учитывать большое количество факторов внутренней и внешней среды, которые могут повлиять на количественные показатели, установленные организацией как целевые ориентиры. При формировании и реализации стратегии учитывают этап развития организации, ее отличительные особенности и возможности.

Основной целью при планировании корпоративной стратегии должно быть создание отличного от других пути развития, который основывается на всех ресурсах и навыках, что является противопоставлением ограничений окружающей среды. Из этого можно сделать вывод, что ключевыми элементами стратегического решения выступают: устойчивость, отличие, предложение конкурентного преимущества, использование связей между организациями и окружающей средой.

Задача стратегического планирования в этом случае заключается в согласовании целей таким образом, чтобы они стали взаимодополняющими. Через систему формулирования целей стратегическое планирование можно представить следующим образом (рис. 1).

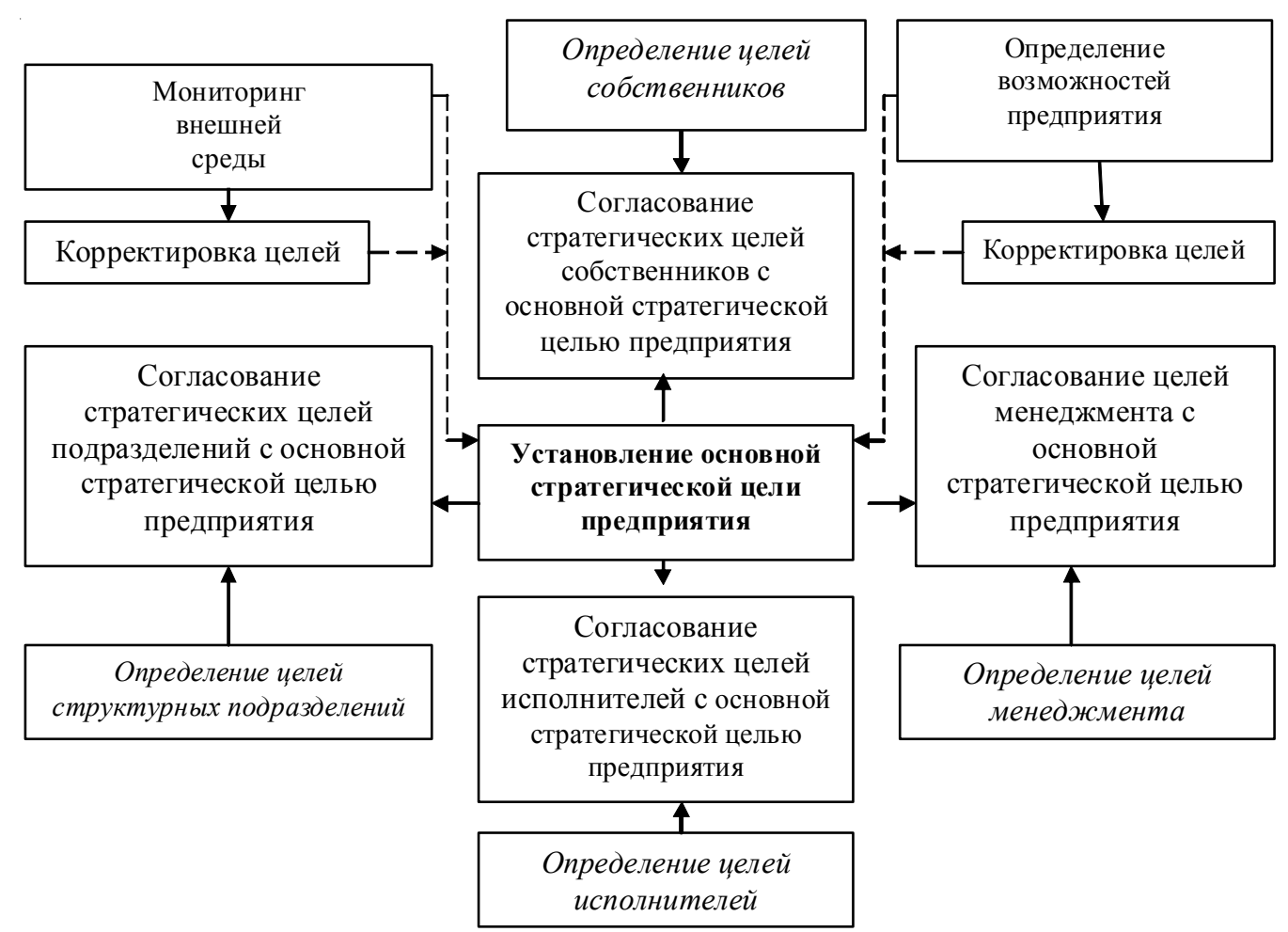

Рис. 1. Согласование целей стратегического планирования

Примечание. Составлено авторами. 


\section{СОЦИАЛЬНО-ЭКОНОМИЧЕСКОЕ РАЗВИТИЕ РЕГИОНОВ}

Сначала цели организации и функционирования предприятия формулируются, как правило, на содержательном (качественном) уровне, что позволяет судить лишь об общем предполагаемом направлении развития системы.

Но уже на этом этапе может возникнуть потребность в интеграции целевых ориентиров, установленных различными заинтересованными сторонами. Любые индивидуальные цели могут реализовываться в рамках организационных ограничений и обязанностей. Обязанности можно рассматривать при этом как сознательно принятые ограничения. В свою очередь, ограничения представляют собой рамки, внутри которых они действуют, тогда как цели - это задачи, которые фирма пытается выполнить [1].

Изменения внешней среды и возможностей организации должны влиять только на стратегические цели предприятия, а уже через прохождение процедуры согласованности этих целей с индивидуальными целями (собственников, менеджмента, структурных подразделений, исполнителей) влиять и на них.

В ходе исследований выявлено, что предприятие, определяя свое положение на рынке при формулировке стратегии, может стремиться к достижению следующих стратегических целей, которые выступают исходными задачами стратегического планирования:

- сконцентрироваться на привлекательных рынках;

- увеличить рыночный сегмент; позиции.

- удержать существующие рыночные

Для реализации исходных задач используется ограниченное количество базовых стратегических задач, среди которых наиболее распространенными являются изменение рыночных приоритетов или рыночных сегментов, внедрение инноваций, повышение качества товаров, использование конкурентных преимуществ высокого или низкого порядка, диверсификация деятельности, повышение эффективности составляющих внутренней среды организации.

Выходные задачи стратегического планирования должны соответствовать реальным возможностям предприятия и быть направлены на максимально возможное использование имеющегося потенциала предприятия.
В качестве объекта исследования выбраны индустриальные предприятия пищевой промышленности.

Согласно статистическим данным, пищевая и перерабатывающая промышленность в структуре промышленного производства России занимает свыше 10 \% и относится к лидерам по выпуску промышленной продукции (наряду с топливной и металлургической промышленностью).

Пищевая и перерабатывающая промышленность включает в себя более 30 отраслей, в ее состав входят свыше 40 тыс. предприятий, где занято более 1 млн человек.

Пищевая и перерабатывающая промышленность остается инвестиционно привлекательной, это демонстрирует динамика объемов инвестиционных вложений в ее модернизацию, которые в 2016 г. составили 136,1 млрд руб., что на 10,3 \% больше, чем в 2015 году.

Наибольшая доля инвестиций в настоящее время наблюдается в мясной и молочной отраслях. Представляет интерес для инвесторов кондитерская, сахарная, хлебопекарная, плодоовощная и мукомольно-крупяная отрасли.

Основными системными проблемами, характерными для всех отраслей пищевой и перерабатывающей промышленности, являются:

1) недостаток сельскохозяйственного сырья с определенными качественными характеристиками для промышленной переработки;

2) моральный и физический износ технологического оборудования;

3) низкий уровень конкурентоспособности на внутреннем и внешнем продовольственных рынках;

4) неразвитая инфраструктура хранения, транспортировки и логистики товародвижения продукции;

5) высокая волатильность цен на сельскохозяйственное сырье (зерно, мясо, масличные).

Оценка внешней среды помогает предприятию корректировать свою конкурентную позицию, улучшать управленческую деятельность и выигрывать конкурентную борьбу в мировой экономике.

Способность организации реагировать и справляться с изменениями во внешней среде 
Д.В. Нехайчук, Ю.С. Нехайчук. К вопросу стратегического развития предприятий пищевой индустрии

является одной из составляющих успеха и способностью выживать. Вместе с тем эта способность является условием осуществления запланированных стратегических изменений.

В экономической литературе принято внешнее окружение классифицировать по двум характеристикам [4; 7]:

- степень простоты или сложности среды;

- степень стабильности или нестабильности (динамичности) событий. Неопределенность среды возрастает с увеличением динамичности или осложнением ее условий. Степень динамичности внешнего окружения определяется темпом и частотой изменений.

Измерение неопределенности внешней среды осуществляется по принципу «простая сложная» и «стабильная - нестабильная».

«Простой» считается ситуация, которая характеризуется незначительным количеством подобных внешних факторов.

Принцип «сложной» ситуации касается моментов времени, в которые на деятельность предприятия будет действовать большое количество непохожих факторов.

Сложность факторов возникает в результате количества видов деятельности предприятия, специализации деятельности, состояния экономической и политической стабильности в стране, развития рыночной инфраструктуры.

Так, предприятия, осуществляющие внешнеэкономическую деятельность, попадают в зависимость от внешнеэкономической политики своей страны и стран его контрагентов. Специализация деятельности определяет зависимость стратегии деятельности от состояния спроса на товары. Узкая специализация деятельности в условиях меняющегося (сезонного) спроса увеличивает фактор риска в деятельности предприятия. Состояние экономики определяет стабильность экономической политики в стране.

В условиях наличия признаков нестабильности в экономике, которые имеют проявление в явлениях дефицитов государственных бюджетов, рост числа лиц, находящихся на грани бедности, рост безработицы, уменьшение покупательной способности населения, рост инфляции, неопределенность окружающей среды растут.

Частые смены правительств страны влекут адекватные их политике изменения в ре- гуляторной политике, увеличивают рискованность деятельности предприятий в условиях выборов.

Факторы внешней среды могут меняться с разной скоростью. Темпы изменения внешней среды характеризуют принцип «стабильности - нестабильности». Одни факторы имеют тенденцию меняться часто, другие проявляют относительную стабильность и частота их изменений незначительна. Частота изменения факторов для предприятий, которые являются переработчиками сельскохозяйственного сырья, совпадает с периодами массовых сборов урожаев и поставок продукции из них.

Отрасли пищевой промышленности работают в различных условиях сложности и нестабильности внешней среды.

Американский ученый П. Дойль, объединив 4 группы факторов неопределенности внешней среды в единую матрицу, сформировал систему оценки неопределенности внешней среды (см. рис. 2).

В состоянии «простое - стабильное»: среда неопределенности низкая. Факторы внешней среды несложно можно проанализировать, а их изменение во времени происходит медленно.

Состояние «сложное - стабильное»: среда характеризуется ростом неопределенности. Для данного состояния внешней среды характерно обилие факторов, прогноз влияния которых на деятельность предприятия осуществить сложнее, поэтому и рискованность деятельности растет. Однако при значительном количестве факторов они не отличаются быстрой изменчивостью.

Состояние «простое - нестабильное»: среда характеризуется незначительным количеством факторов внешней среды, но быстрой изменчивостью.

Состояние «сложное - нестабильное»: среда сопровождается высокой неопределенностью внешней среды. Количество факторов, которые влияют на деятельность предприятия, является значительным, факторы имеют тенденцию скорой изменчивости. Определяющим в «сложном - нестабильном» состоянии среды является непредсказуемость изменений внешней среды, которая может стать причиной резких изменений стратегий разви- 


\begin{tabular}{|c|c|c|c|}
\hline & \multicolumn{2}{|c|}{ Сложность среды } \\
\hline & & Простая & Сложнная \\
\hline \multirow{4}{*}{ 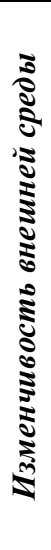 } & \multirow[b]{2}{*}{ 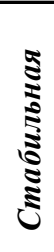 } & $\begin{array}{l}\text { Простая + стабильная = низкая не- } \\
\text { определенность }\end{array}$ & $\begin{array}{l}\text { Сложная + стабильная = неопреде- } \\
\text { ленность от низкой до средней }\end{array}$ \\
\hline & & $\begin{array}{l}\text { Небольшое кол-во внешних факторов, } \\
\text { факторы подобны. } \\
\text { Факторы среды изменяются свободно. } \\
\text { Производство минеральной воды }\end{array}$ & $\begin{array}{l}\text { Большое кол-во внешних факторов, } \\
\text { факторы неподобны. } \\
\text { Факторы среды изменяются свободно. } \\
\text { Кондитерская промышленность }\end{array}$ \\
\hline & & $\begin{array}{l}\text { Простая }+ \text { нестабильная }=\text { неопреде- } \\
\text { ленность от низкой до средней }\end{array}$ & $\begin{array}{l}\text { Сложная }+ \text { нестабильная }=\text { высокая } \\
\text { неопределенность }\end{array}$ \\
\hline &  & $\begin{array}{l}\text { Небольшое кол-во внешних факторов, } \\
\text { факторы подобны. } \\
\text { Факторы среды изменяются часто и } \\
\text { непредвиденно. } \\
\text { Ликероводочная, пивобезалкогольная } \\
\text { промышленность }\end{array}$ & $\begin{array}{l}\text { Большое кол-во внешних факторов, } \\
\text { факторы неподобны. } \\
\text { Факторы среды изменяются часто и } \\
\text { непредвиденно. } \\
\text { Масло-жировая, сахарная, молочная, } \\
\text { мясная промышленность }\end{array}$ \\
\hline
\end{tabular}

Рис. 2. Матрица оценки неопределенности внешней среды предприятия

Примечание. Составлено по: [3].

тия предприятия вплоть до применения стратегии банкротства.

Необходимость анализа возможного состояния неопределенности продиктована потребностями предприятия в разработке стратегии развития. Учитывая критерии сложности факторов и изменчивость внешней среды, в обобщенном виде стратегии развития предприятия можно сгруппировать в пять укрупненных групп (см. таблицу, рис. 3):

- оставить все без изменений;

- выбрать стратегию внутреннего роста;

- выбрать стратегию внешнего роста;

- выбрать стратегию внешнеэкономической деятельности; тиций

- выбрать стратегию изъятия инвес-

Стратегия «без изменений» чаще всего используется теми из предприятий, которые являются производителями традиционного узкоассортиментного продукта или являются полуфабрикатом для дальнейшей переработки в других отраслях производства. Использование данной стратегии дает определенные преимущества для предприятия в виде отсутствия расходов на проведение мероприятий по стимулированию сбыта. Одновременно данная стратегия связана с определенными недостатками, которые выражаются в отсутствии возможностей для развития товара. Среди предприятий пищевой промышленности данная стратегия используется предприятиями масложировой промышленности.
Стратегия внутреннего роста реализуется только в условиях наличия достаточного количества сырьевых ресурсов и неудовлетворенного спроса. Объектами усилий предприятия является рынок и товар, поэтому стратегия внутреннего роста реализуется через конкретные стратегии: разработка новых товаров, усовершенствование (обновление) существующего ассортимента, рост доли рынка, концентрация.

Стратегия внешнего роста используется предприятиями, которые умеют использовать факторы внешней среды в свою пользу, имея при этом достаточное количество финансовых возможностей для реализации конкретных стратегий слияния, поглощения, присоединения, интеграции, диверсификации. Насыщенность внутреннего рынка, ограниченные возможности по росту внутреннего спроса в совокупности с активизацией политики протекционизма в странах потенциальных потребителей российской продукции побуждает предприятия кондитерской промышленности к приобретению активов в бывших социалистических странах ввиду сходства традиций ассортимента.

Возможности использования стратегий внешнего роста имеют сегодня и предприятия хлебопекарной, плодовоовощной и консервной промышленности.

Стратегия внешнеэкономической деятельности предусматривает усиление акцентов в деятельности предприятий на выходе за 
Отраслевые стратегии развития предприятий пищевой промышленности

\begin{tabular}{|l|c|c|c|c|c|}
\hline \multirow{2}{*}{$\begin{array}{c}\text { Подотрасли } \\
\text { пищевой } \\
\text { промышленности }\end{array}$} & $\begin{array}{c}\text { без } \\
\text { изменений }\end{array}$ & $\begin{array}{c}\text { стратегия } \\
\text { внутреннего } \\
\text { роста }\end{array}$ & $\begin{array}{c}\text { стратегия } \\
\text { внешнего } \\
\text { роста }\end{array}$ & $\begin{array}{c}\text { стратегия } \\
\text { внешнеэко- } \\
\text { номической } \\
\text { деятельности }\end{array}$ & $\begin{array}{c}\text { изъятие ин- } \\
\text { вестиций }\end{array}$ \\
\hline Сахарная & & + & & & \\
\hline Хлебопекарная & & & + & + & \\
\hline Масло-жировая & + & + & + & + & \\
\hline Плодовоовощная & & + & & & \\
\hline $\begin{array}{l}\text { Мукомольно- } \\
\text { крупяная }\end{array}$ & & + & & & \\
\hline Молочная & & + & & & \\
\hline Мясная & & + & & + & \\
\hline Кондитерская & & &
\end{tabular}

Примечание. Составлено авторами по: [9].

\begin{tabular}{|c|c|c|c|}
\hline & \multicolumn{2}{|c|}{ Сложность среды } \\
\hline & & Простая & Сложная \\
\hline \multirow{4}{*}{ 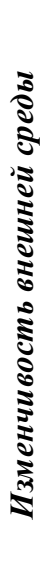 } & \multirow{2}{*}{ 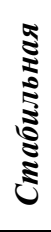 } & $\begin{array}{l}\text { Простая + стабильная }=\text { низкая } \\
\text { определенность }\end{array}$ & $\begin{array}{l}\text { Сложная }+ \text { стабильная }=\text { неопределенность } \\
\text { от низкой до средней }\end{array}$ \\
\hline & & $\begin{array}{l}\text { Концентрация. } \\
\text { Увеличение части рынка }\end{array}$ & $\begin{array}{l}\text { Разработка нового товара. } \\
\text { Концентрация. } \\
\text { Интеграция }\end{array}$ \\
\hline & \multirow{2}{*}{ 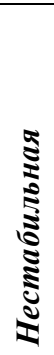 } & $\begin{array}{l}\text { Простая + нестабильная = } \\
\text { неопределенность от низкой } \\
\text { до средней }\end{array}$ & $\begin{array}{l}\text { Сложная + нестабильная }=\text { высокая } \\
\text { неопределенность }\end{array}$ \\
\hline & & $\begin{array}{l}\text { Обновление продукции. } \\
\text { Диверсификация }\end{array}$ & $\begin{array}{l}\text { Диверсификация. } \\
\text { Интеграция. } \\
\text { Оставить без изменений. } \\
\text { Продажа }\end{array}$ \\
\hline
\end{tabular}

Рис. 3. Стратегии предприятия в условиях неопределенности внешней среды

Примечание. Составлено авторами по: [5].

пределы национальных границ. Близость большинства рынков РФ до состояния насыщенности, с одной стороны, и необходимость поиска направлений роста, с другой стороны, заставляют предприятия искать пути экспорта своей продукции.

Стратегия изъятия инвестиций применяется владельцами по отношению к тем предприятиям, которые выявили низкую эффективность использования ресурсов или рыночная стоимость которых в условиях конъюнктуры на рынке данных активов высока и продажа предприятия будет более эффективна по сравнению с его дальнейшей эксплуатацией. К конкретным стратегиям изъятия инвестиций можно отнести стратегию продаж и стратегию ликвидации.
Стратегии, определенные для отраслей пищевой промышленности в соответствии с условиями неопределенности воздействия внешней среды, позволят уменьшить негативное воздействие окружающей среды и обеспечить стабильность деятельности предприятий.

При осуществлении анализа текущей ситуации в отрасли используются следующие четыре методики [8]:

- оценка влияния факторов макросреды, которая определяет общие условия игроков отрасли. В зависимости от объемов и характера бизнеса приоритетное значение приобретают различные группы факторов: политические, экономические, социальные, правовые, технологические, международные, природно-климати- 
ческие и т. д. Определение влияния этих факторов и осуществление прогноза их влияния позволяют предвидеть возможные проблемы стратегического развития предприятий;

- определение движущих сил отрасли используется для выяснения, анализа, динамики и прогноза процессов, которые определяют изменения в жизни отрасли. Примерами применения этой методики могут быть использование полученных результатов для учета возможных рисков при избрании вариантов стратегического поведения или при оценке имиджа предприятия;

- выяснение и оценка ключевых факторов успеха (КФУ). Эта методика позволяет выяснить способность производителей отрасли наиболее эффективно вести соответствующий бизнес. КФУ - это отраслевые характеристики, которые не зависят от возможностей и слабостей конкретного предприятия. Неудовлетворительное состояние КФУ влечет за собой необходимость существенного повышения затрат ресурсов;

- определение групп влияния. С помощью этой методики можно определить перечень групп влияния отрасли, оценить степень противодействия или поддержки деятельности предприятия в целом. К движущим силам, как правило, относят: продуктовые инновации, инновации в маркетинге, долгосрочное изменение спроса, вход и выход из отрасли крупных предприятий, изменения государственной политики, изменения в расходах и эффективности и т. д. Учет основных движущих сил отрасли требуется для соответствия потенциала предприятия требованиям, предъявляемым отраслью.

Для определения текущей и перспективной устойчивости предприятий делаются оценки влияния факторов, характеризующие общие условия развития всех представителей отрасли. Наиболее распространенным в использовании является анализ по методике, предложенной А. Томпсоном и Дж. Стриклендом, по которой определяются основные экономические характеристики отрасли.

Анализ осуществляется по следующим параметрам: размеры рынка; масштаб конкуренции; темпы роста рынка; стадия жизненного цикла, количество предприятий в отрасли; потребители; конкуренты в отрасли, степень вертикальной интеграции; вход и выход из отрасли; технологии, инновации; характеристики продукции; экономия на масштабе производства; эффект обучения; загруженность производственных мощностей; прибыльность отрасли [10].

Предпочтение определенной стратегии развития отрасли зависит от существующих позиций и позиций, которые будут достигнуты в результате реализации предыдущих стратегий, специфики товаров, работающих на рынке, состояния рынка и степени конкурентной борьбы на нем, развития государственного регулирования, ресурсного потенциала отрасли.

\section{СПИСОК ЛИТЕРАТУРЫ}

1. Ансофф, И. Новая корпоративная стратегия / И. Ансофф. - СПб. : Питер Ком, 1999. - 416 с.

2. Виханский А. С. Стратегическое управление : учебник / А. С. Виханский. - 2-е изд., перераб. и доп. - М. : Гардарика, 2008. - 296 с.

3. Дойль, П. Менеджмент: стратегия и тактика : пер. с англ. / П. Дойль ; под. ред. Ю. Н. Каптуревского. - СПб. : Питер, 2001. - 480 с.

4. Кныш, М. И. Стратегическое управление корпорациями / М. И. Кньш, В. В. Пучков, Ю. П. Тютиков. - СПб. : Культ-информ-пресс, 2012.- 239 с.

5. Люкшинов, А. Н. Стратегический менеджмент : учеб. пособие / А. Н. Люкшинов. - М. : ЮНИТИ-ДАНА, 2010. -375 с.

6. Маркова В. Д. Стратегический менеджмент : курс лекций / В. Д. Маркова, С. Кузнецова. М. : Инфра-М, 2010. - 287 с.

7. Нехайчук, Д. В. Мониторинг и оценивание как составляющие бюджетных программ / Д. В. Нехайчук, Ю. С. Нехайчук // Научный вестник: финансы, банки, инвестиции. - 2012. - № 5 (18). - С. 53-59.

8. Нехайчук, Ю. С. Стратегическое планирование как инструмент региональной политики: Крымский аспект / Ю. С. Нехайчук, Д. В. Нехайчук // Символ науки. - 2015. - № 8. - С. 107-119.

9. Распоряжение Правительства РФ от 17 апр. 2012 г. № 559-р «О Стратегии развития пищевой и перерабатывающей промышленности РФ на период до 2020 г.». - Элеткрон. текстовые дан.. - Режим доступа: http://docs.cntd.ru/document/902343994. Загл. с экрана.

10. Томпсон, А. А. Стратегический менеджмент: концепции и ситуации для анализа / А. А. Томпсон, А. Дж. Стрикленд. - М. : Вильямс, 2012. $928 \mathrm{c}$.

11. Шершнева, 3. Е. Стратегическое управление / 3. Е. Шершнева, С. В. Оборская. Симферополь : КНЭУ, 2009. - 348 с. 
Д.В. Нехайчук, Ю.С. Нехайчук. К вопросу стратегического развития предприятий пищевой индустрии

\section{REFERENCES}

1. Ansoff I. Novaya korporativnaya strategiya [New Corporate Strategy]. Saint Petersburg, Piter Kom Publ., 1999. 416 p.

2. Vikhanskiy A.S. Strategicheskoe upravlenie: uchebnik [Strategic Management: Textbook]. Moscow, Gardarika Publ., 2008. 296 p.

3. Doil P. Menedzhment: strategiya i taktika [Management: Strategy and Tactics]. Saint Petersburg, Piter Publ., 2001. 480 p.

4. Knysh M.I., Puchkov V.V., Tyutikov Yu.P. Strategicheskoe upravlenie korporatsiyami [Strategic Management of Corporations]. Saint Petersburg, Kult-inform-press, 2012. 239 p.

5. LyukshinovA.N. Strategicheskiymenedzhment [Strategic Management]. Moscow, YuNITI-DANA Publ., 2010.375 p.

6. Markova V.D., Kuznetsova S. Strategicheskiy menedzhment: kurs lektsiy [Strategic Management. Lecture Course]. Moscow, Infra-M Publ., 2010. 287 p.

7. Nekhaychuk D.V., Nekhaychuk Yu.S. Monitoring i otsenivanie kak sostavlyayushchie byudzhetnykh programm [Monitoring and Evaluation as Components of Budget Programs]. Nauchnyy vestnik: finansy, banki, investitsii, 2012, no. 5 (18), pp. 53-59.

8. Nekhaychuk Yu.S., Nekhaychuk D.V. Strategicheskoe planirovanie kak instrument regionalnoy politiki: Krymskiy aspekt [Strategic Planning as an Instrument of Regional Policy: The Crimean Aspect]. Simvol nauki, 2015, no. 8, pp. 107-119.

9. Rasporyazhenie Pravitelstva RF ot 17 apr. 2012 g. № 559-r «O Strategii razvitiya pishchevoy $i$ pererabatyvayushchey promyshlennosti $R F$ na period do 2020 g.» [Decree of the Government of the Russian Federation of April 17, 2012 no. 559-r "On the Strategy for the Development of the Food and Processing Industries of the Russian Federation for the Period till 2020"]. URL: http://docs.cntd.ru/ document/902343994.

10. Tompson A.A., Striklend A.Dzh. Strategicheskiy menedzhment: kontseptsii i situatsii dlya analiza [Strategic Management: Concepts and Situations for Analysis]. Moscow, Williams Publ., 2012. $928 \mathrm{p}$.

11. Shershneva Z.E., Oborskaya S.V. Strategicheskoe upravlenie [Strategic Management]. Simferepol, KNEU Publ., 2009. 348 p.

\section{Information about the Authors}

Dmytriy V. Nekhaychuk, Doctor of Sciences (Economics), Associate Professor, Head of Department of Finance and Mathematical Methods in Economics, Crimean Business Institute, Yuzhnaya St., 39, 297536 Sovkhoznoe Village, Simferopol Region, Republic of Crimea, Russian Federation, dimchikn@mail.ru.

Yulia S. Nekhaychuk, Candidate of Sciences (Economics), Associate Professor, Department of Finance of Enterprises and Insurance, Crimean Federal University named after V.I. Vernadsky, Prosp. Vernadskogo, 4, 295007 Simferopol, Republic of Crimea, Russian Federation, elekobec@mail.ru.

\section{Информация об авторах}

Дмитрий Валериевич Нехайчук, доктор экономических наук, доцент, заведующий кафедрой финансов и математических методов в экономике, Крымский институт бизнеса, ул. Южная, 39, 297536 с. Совхозное, Симферопольский район, Республика Крым, Российская Федерация, dimchikn@mail.ru.

Юлия Серафимовна Нехайчук, кандидат экономических наук, доцент кафедры финансов предприятий и страхования, Крымский федеральный университет им. В.И. Вернадского, просп. акад. Вернадского, 4, 295007 г. Симферополь, Республика Крым, Российская Федерация, elekobec@mail.ru. 